\title{
An Overview of Extended Spectrum Beta Lactamases and Metallo Beta Lactamases
}

\author{
Kavita Nagshetty' ${ }^{1}$ B. M. Shilpa ${ }^{2}$, Shripad A. Patil ${ }^{3}$, C. T. Shivannavar ${ }^{1}$, N. G. Manjula ${ }^{2 *}$ \\ ${ }^{1}$ Department of P. G. Studies and Research in Microbiology, Gulbarga University, Gulbarga, India \\ ${ }^{2}$ Department of Microbiology, School of Basic and Applied Sciences (SBAS), Dayananda Sagar University, Bengaluru, Karnataka, India \\ ${ }^{3}$ ICMR-National JALMA Institute for Leprosy and Other Mycobacterial Diseases, Agra, Uttar Pradesh, India \\ Email: *manjulang-sbas@dsu.edu.in
}

How to cite this paper: Nagshetty, K., Shilpa, B.M., Patil, S.A., Shivannavar, C.T. and Manjula, N.G. (2021) An Overview of Extended Spectrum Beta Lactamases and Metallo Beta Lactamases. Advances in Microbiology, 11, 37-62.

https://doi.org/10.4236/aim.2021.111004

Received: December 17, 2020

Accepted: January 25, 2021

Published: January 28, 2021

Copyright $\odot 2021$ by author(s) and Scientific Research Publishing Inc. This work is licensed under the Creative Commons Attribution International License (CC BY 4.0).

http://creativecommons.org/licenses/by/4.0/

\begin{abstract}
Antibiotic resistant $\beta$-lactamases are diverse and complex enzymes produced by most of the Gram-negative bacteria that are mediated by number of plasmids. The impact of these enzymes has posed a major threat to the health sectors and has challenged the available treatment options for both community and hospital acquired infections. These include the uncomplicated most severe life-threatening infections. Moreover, with resistance to the cephalosporin drugs these Multidrug Resistance strains exhibit co-resistance patterns with different class of antibiotics which is a cause of concern that leads to narrow the limited treatment options. It is alarming situation since there is a steep rise in MDR - Beta lactamase pathogens mainly in Escherichia coli, Klebsiella pneumoniae, Acinetobacter baumannii and Pseudomonas aeruginosa. Currently, the clinical detection of Extended Spectrum of $\beta$-Lactamases $(\mathrm{ES} \beta \mathrm{L})$ and $\mathrm{M} \beta \mathrm{L}$ producing pathogens are carried out by antibiotic sensitivity test on the guidelines of Clinical and Laboratory Standards Institute (formerly the National Committee for Clinical Laboratory Standards) since, the other methods being too expensive. The choice of antimicrobial treatment for infections should rely on the clinical data and the tests (AST) in asymptomatic and mild cases. However, this does not imply for critical infections. The last resorts of treatment for ES $\beta \mathrm{L}$ pathogens are carbapenem and nevertheless, resistances have also been reported for the same. With increasing resistance rate to the antibiotics, it is very essential to follow the guidelines for detection, implementation of antibiotic rotation to reduce these pathogens, followed by the efficient infection control practices and strategies to avoid such outbreaks.
\end{abstract}

\section{Keywords}

$\mathrm{ES} \beta \mathrm{L}, \mathrm{M} \beta \mathrm{L}, \mathrm{MDR}$ 


\section{Introduction}

Infectious diseases are the potential transmission of a pathogenic agent from one species to another and these pathogens are contagious, which are also known as communicable diseases [1]. These pathogens have shown high resistance to the antibiotics, which has become a worldwide problem with the consequences on the infectious disease's treatment. Usually antibiotics are given empirically before the laboratory results of culture are available to ensure appropriate therapy. There is an alarming increase of antibiotic resistance in bacteria that cause either community infections or hospital acquired infections. Many of these multidrug pathogens are of particular interest such as, Escherichia coli, Klebsiella pneumoniae, Acinetobacter baumannii, methicillin-resistant Staphylococcus aureus, penicillin-resistant Streptococcus pneumoniae, vancomycin-resistant Enterococcus, and extensively drugs resistant Mycobacterium tuberculosis [2] .

According to WHO (2018) reports, 750,000 deaths every year may shoot high due to bacteria exhibiting resistance if proper action is not taken. Hence, antibiotic resistance has become one of the greatest threats to global health and survival statistics, which may be linked to global problem. Dispersion of the successful clones of Multidrug Resistant (MDR) bacteria is found to be common with the importance of plasmids carrying MDR markers in Shigella sps., and $E$. coli first described in the seminal work in Japan over 57 years ago [3]. Leplae and his coworkers (2006) showed the mechanism of transmission of mosaic plasmids from one bacterium to other to give rise to the MDR phenotype [4].

$\beta$-lactam antibiotics are the most common drugs used for the treatment of Gram-negative bacteria and their continuous misuse has led to the resistance worldwide [5]. Bacterial strains have induced continuous production and mutation of $\beta$-lactamases, due to the continuous exposure Beta lactam drugs, expanding their activity even against the newly developed $\beta$-lactam antibiotics. Incidence and treatment of ES $\beta \mathrm{L}$-producing MDR strains is a matter of scientific concern for the difficulties to resolve due to various reasons, difficulty in detecting ES $\beta \mathrm{L}$ production and inconsistencies in reporting [6]. Recently, a significant increase in the incidents of ES $\beta$ L-related infections has been observed throughout the globe [7] [8].

Microorganisms that produce beta-lactamases can break and enable the beta-lactam molecules inactive thus, conferring the resistance to the pathogens. More than 500 beta-lactamases have been reported so far

(http://www.lahey.org/studies). These beta-lactamases are widespread across the world that are mostly reported in Gram negative organisms with common resistance mechanism mediated by plasmid or expressed chromosomally, specifically the CTX-M-15 family. Chromosomally located inducible expression is also common, while plasmid mediated enzymes are generally expressed constitutively in these Gram-negative organisms [9] [10].

ES $\beta$ L enzymes are commonly found in the members of Enterobacteriaceae family and are of over 120 types. ES $\beta$ Ls are generally acquired by horizontal gene 
transfer and confer resistance to oxyimino-cephalosporins, some being mutant derivatives of established plasmid-mediated $\beta$-lactamases (TEM/SHV) or mobilized from environmental bacteria (CTX-M) and these enzymes hydrolyze penicillin, broad-spectrum cephalosporins and monobactams. However, they do not affect cephamycin and carbapenems, and they are inhibited by clavulanic acid [11]. ES $\beta$ L has generally been defined as transmissible $\beta$-lactamases that can be inhibited by clavulanic acid, tazobactam or sulbactam, and which are encoded by genes that can be exchanged between bacteria [11]. Clavulanic acid is used in combination with amoxicillin and ticarcillin, sulbactam sodium is used in combination with ampicillin and cefoperazone, and tazobactam in combination with piperacillin [12].

Emergence of Metallo- $\beta$-Lactamases (M $\beta$ Ls) with activity against carbapenems (e.g. the VIM and IMP families of enzymes) has compromised the clinical utility of this class of antibiotics [13] [14]. Resistance to carbapenems may also be induced as a result of increased production of either AmpC or ES $\beta \mathrm{L}$, coupled with a decrease in porin production or increased efflux [14] [15]. In India, the high rates of ES $\beta \mathrm{L}$ producers have recently increased the usage of carbapenem antibiotics, which may provide a selective pressure for the spread of strains producing carbapenems in the near future [16] [17].

\section{Mechanism of Antibiotic Resistance by Beta-Lactamases}

In the year 1940, $\beta$-lactam antibiotics came into clinical use and it has been observed that many strains of bacteria have emerged resistant to these drugs [18]. Resistance to these agents is in both Gram-positive and Gram-negative bacterial pathogens and occurs as a result of drug inactivation by $\beta$-lactamases, target site (i.e. PBP) alterations, diminished permeability and efflux of drugs [19]. The primary mechanism of the $\beta$-lactam resistance is by enzymatic cleavage of the $\beta$-lactam ring by $\beta$-lactamases produced by microbes [18].

In 1983, SHV-2, a plasmid borne ES $\beta$ L produced by $K$. ozaenae was discovered in Germany. Other ES $\beta$ L types, TEM and SHV were predominant until 1990. Later on, prevalence of SHV, TEM and a new CTX-M family of ES $\beta$ L coproduced mainly by E. coli had emerged. CTX-M has become the predominant and CTX-M-producing $E$. coli has spread globally and has been involved in nosocomial outbreaks and community acquired infections [20]. In 1990 the first blaCTX-M was detected in clinically isolated E. coli in Germany [21] then on CTX-M-producing Enterobacteriaceae has been detected globally [22] [23].

Beta-lactamases producing bacteria hydrolyse beta-lactam drugs and render them inactive before it gets to the PBP (Penicillin binding proteins) target. The structural similarities with PBP makes the lactamases bind acylate and hydrolyse using water molecules and inactivate the Beta lactam drugs. These enzymes contain either serine residue (Ambler classes A, C, D) or metal ion $\mathrm{Zn}^{2+}$ (Ambler class $\mathrm{B}$ ) in their active site, that attack beta-lactam ring and break the amide bond in the ring Figure 1 [24] [25] [26]. 


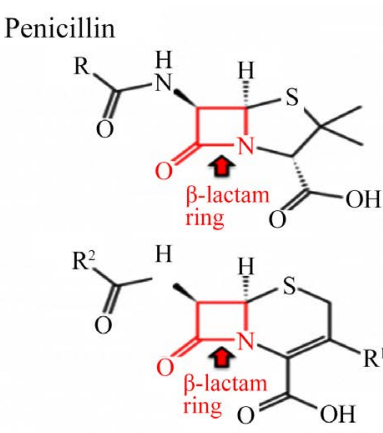

Cephalosporin

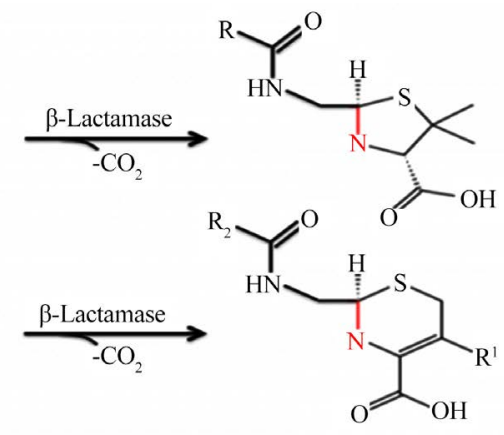

inactive metabolites

Figure 1. Interaction between antibiotic and beta-lactamases.

\section{Structure of Beta Lactamases}

\subsection{Primary Structure/Molecular Structure}

Largest group of class A-lactamases was characterized on the basis of 26 strictly conserved residues and molecular comparisons helped standard numbering scheme as indicated by the label "ABL" (for class A-lactamase) [27]. Further updated list was reported for the residues that are involved in the catalytic mechanism and/ or in substrate binding by Matange et al. [28] [29].

It has been reported that, 268 sequences aligned for representative of class A-lactamases from subclasses A1 and A2, 100\% was confirmed and highly conserved (between 90\% and 99\%) residues, such as Gly45, Ser70, Lys73, Leu81, Pro107, Ser130, Asp131, Asn132, Ala134, Gly144, Gly156, Glu166, Lys/ Arg234, Thr/Ser235, and Gly236, differentiated between subclasses. The two subclasses were distinguished as A1 [28] [29] [30] and A2 (discovered more recently) as subgroups due to their different conserved residues. PER-1 and PER-2, an alignment of subclass A2-lactamase sequences revealed the presence of several insertions [31] [32]. An examination of the overall amino acid composition of lactamases revealed that representative enzymes from subclass A2 had small numbers of arginine residues (8.2 3.9 residues on average) and large numbers of lysine residues (29.0 5.5 residues).

\subsection{Structure-Function Relationships of Class A Enzymes}

A great diversity of amino acid sequences has been noted between the different clusters of class A $\beta$-lactamases and further, X-ray crystallography has been able to determine the tertiary structure of these protein molecules and helped to explore the two subclasses of $\mathrm{A} 1$ and A2.

(http://www.rcsb.org/pdb/home/home.do). Structures of Beta lactamases such as, TEM types, SHV types, CTX-M types, KPC-2, L2, NMC-A, OXY-1, PenA, PenI, PSE-4, SED-1, SME-1, Toho-1, and Francisella tularensis that are produced by Gram negative organisms have been determined with the exception of PER-1 and PER-2, belong to subclass A1 [31] [32].

Overall structures of these are found to be same with the structural features 
surrounding the active sites with two subdomains generating a cleft as in Figure 2 [28] [33] [34]. Of the two sub domains, the alpha subdomain is largely $\alpha$-helical in contrast, to the alpha/beta subdomain that consists of a five-stranded $\beta$-sheet flanked by $\alpha$-helices. Active sites are present on the cleft of the two subdomains and contain catalytic Ser70 residue and Glu166, Asn170, and Ser70 that is deacylated with water primed by interactions.

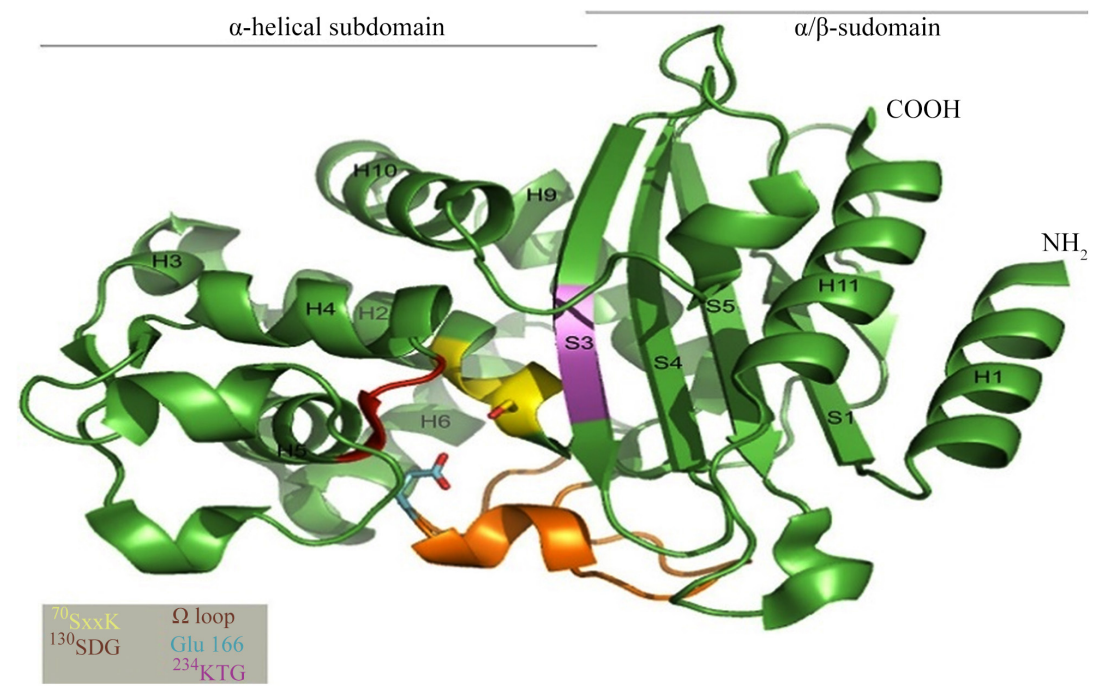

Figure 2. Secondary structures of the class A $\beta$-lactamase of Mycobacterium tuberculosis, with the spatial arrangements of the three catalytic center defining amino acid groupings, the $\alpha$ domain (left), and an $\alpha / \beta$ domain (right) [35]. The helices are represented as $\mathrm{H} 1$ to h11, and the strands are represented as S1 to S5. The figure was created with PyMOL (Delano Scientific).

\section{Extended-Spectrum Beta-Lactamase (ES $\beta \mathrm{L})$}

The term was used initially to refer to TEM and SHV enzymes that have the ability to hydrolyze oxyimino-cephalosporins. Later on, this term has been widened to include:

- Enzymes derived from other sources and have resistance spectra similar to that of TEM and SHV mutants e.g. CTX-M and VEB types.

- Enzymes exhibit wider resistance than their parents but do not belong to 2 be group e.g. OXA and Amp C mutants with increased activity against cefepime [36].

Currently used definition for $\mathrm{ES} \beta \mathrm{L}$ is $\beta$-lactamase that is able to render the bacterium resistant to the penicillin, first, second, and third-generation cephalosporins and aztreonam, but not cephamycins or carbapenems, by hydrolysis that could be inhibited by $\beta$-lactamase inhibitors of these antibiotics [11] [37] [38].

\subsection{Classification of Beta-Lactamases}

According to Ambler molecular classification scheme, which is based on the protein sequence similarity these are classified into four classes A, B, C and D. 
This classification also is based on conserved and variable amino acid motifs of the proteins. Class $\mathrm{A}, \mathrm{C}$, and $\mathrm{D}$ include the enzymes that hydrolyze their substrates by forming acyl enzymes via the active site serine, while class B (metalloenzymes) utilizes active site zinc to facilitate $\beta$-lactam hydrolysis [9] [39].

Bush-Jacoby-Medeiros functional classification scheme classify these enzymes according to the similarity in their functional (substrates and inhibitors profile) characteristics. Although the molecular classification is the easiest scheme to group these diverse enzymes, the functional classification enables the clinicians and laboratory microbiologists to correlate these enzymes with their clinical roles [9]. Table 1 reveals the detailed classification of the $\beta$-lactamases.

Table 1. Classification schemes and representatives of extended spectrum beta-lactamase enzymes.

\begin{tabular}{|c|c|c|c|c|c|}
\hline \multirow{2}{*}{$\begin{array}{c}\text { Ambler } \\
\text { (molecular) } \\
\text { Class }\end{array}$} & \multirow{2}{*}{$\begin{array}{l}\text { Bush \& Jacoby } \\
\text { group (2009) }\end{array}$} & \multirow{2}{*}{ Substrate/target } & \multicolumn{2}{|c|}{ Inhibition profile } & \multirow{2}{*}{ Member examples } \\
\hline & & & Clavulanic acid & azobactam & \\
\hline \multirow{7}{*}{ A } & $2 \mathrm{a}$ & Penicillins & Yes & No & PC-1 \\
\hline & $2 \mathrm{~b}$ & $\begin{array}{l}\text { Penicillins, some of the } 1 \text { st-generation } \\
\text { cephalosporin }\end{array}$ & Yes & No & TEM-1, TEM-2, SHV-1 \\
\hline & $2 \mathrm{be}$ & $\begin{array}{l}\text { Extended spectrum cephalosporin, } \\
\text { monobactam }\end{array}$ & Yes & No & TEM-3, SHV-2, CTX-M-15, PET-1, VEB-1 \\
\hline & $2 \mathrm{br}$ & Penicillins & No & No & TEM-30, SHV-10 \\
\hline & 2ber & $\begin{array}{l}\text { Extended spectrum cephalosporin, } \\
\text { monobactam }\end{array}$ & No & No & TEM-50 \\
\hline & $2 c e$ & Carbenicillin, cefepime & Yes & No & RTG-4 \\
\hline & $2 \mathrm{e}$ & $\begin{array}{l}\text { Extended spectrum } \\
\text { beta-lactams }\end{array}$ & Yes & No & CepA \\
\hline \multirow{2}{*}{ B } & $2 f$ & & Changing & No & KPC-2, 1M1-1, SME-1 \\
\hline & $3 a$ & Carbapenems & No & Yes & IMP-1, VIM-1, CcrA, IND-1, NDM-1 \\
\hline \multirow{3}{*}{$\mathrm{C}$} & $3 b$ & Carbapenems & No & Yes & CphA, Sfh-1 \\
\hline & 1 & Cephalosporins & No & No & AmpC, P99, ACT 1, CMY-2, FOX-1, MIR-1 \\
\hline & $1 \mathrm{e}$ & Cephalosporins & No & Yes & GC1, CMY-37 \\
\hline \multirow{2}{*}{$\mathrm{D}$} & $2 \mathrm{~d}$ & Cloxacillin & Changeable & No & OXA-1, OXA-10 \\
\hline & $2 \mathrm{df}$ & Carbapenems & Variable & No & OXA-23, OXA-48 \\
\hline
\end{tabular}

\section{TYPES OF ES $\beta$ L:}

\subsubsection{TEM}

TEM type ES $\beta$ Ls are derivatives of TEM- 1 and TEM-2.

TEM-1 was detected for the first time in 1965 at Greece among an E. coli isolate recovered from a patient named Temoneira, and hence the designation TEM 
[40]. TEM-1 hydrolyses ampicillin at a rate higher than that of carbenicillin, oxacillin, and cephalothin but fail to hydrolyse the extended-spectrum cephalosporins. TEM-2 has the same hydrolytic activity of TEM-1 but has more active native promotor and a different isoelectric point (5.6 instead 5.4). The plasmid mediated $\beta$-lactamase TEM-3 (an ES $\beta \mathrm{L}$ member) was detected in 1987 in $K$. pneumoniae which was isolated in France. It was originally named CTX-1 due to its higher activity against cefotaxime [41]. There is steep rise in the TEM novel variants that has been reported (Figure 3) from different parts of the world that can be accessed at http://www.lahey.org/Studies/temtable.asp.

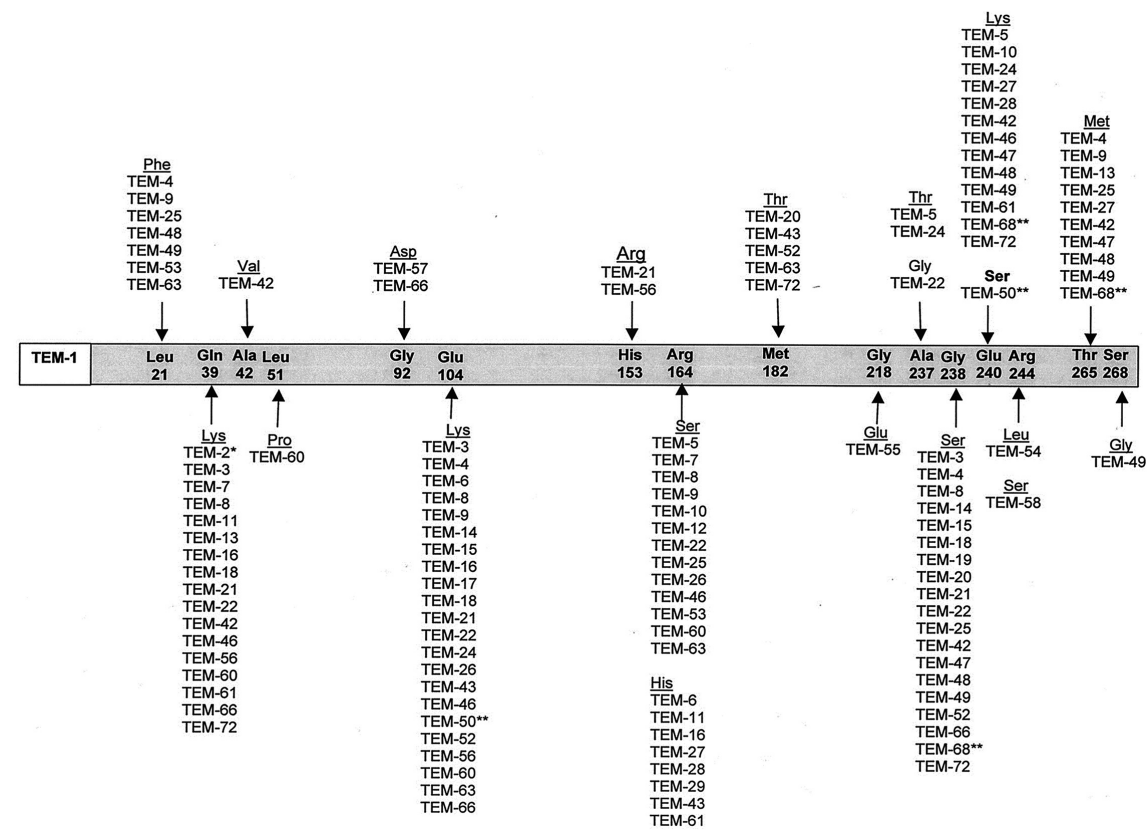

Figure 3. Shows the amino acid substitutions in the different TEM variants in comparison with TEM-1 adapted from Bradford (2001).

\subsubsection{SHV}

SHV-type ES $\beta$ L was the most frequently detected in clinical isolates [42]. This is referred to sulfhydryl variable because it was thought that the inhibition of the enzyme activity by $\mathrm{p}$-chloromercuribenzoate was substrate-dependent and variable according to the substrate used in the assay [43]. In 1983, a new SHV- $\beta$ lactamase (designated SHV-2) efficiently hydrolyzes cefotaxime and to lesser extent ceftazidime had been detected in $K$. ozaenae in Germany [44]. SHV-2 differs from SHV-1 by only one amino acid at the $238^{\text {th }}$ position (glycine replaced by serine). This substitution (Gly238Ser) that resulted from a point mutation accounts for the activity of this enzyme against extended-spectrum cephalosporin. SHV-2 spread globally due to the selection pressure exerted by third- generation cephalosporins being detected in a wide range of Enterobacteriaceae but mainly in Klebsiella sps. [11] [45] [46]. The amino acid sequence compositions for 193 different variants have been reported (Figure 4) and the data can be accessed at http://www.lahey.org/Studies/. 


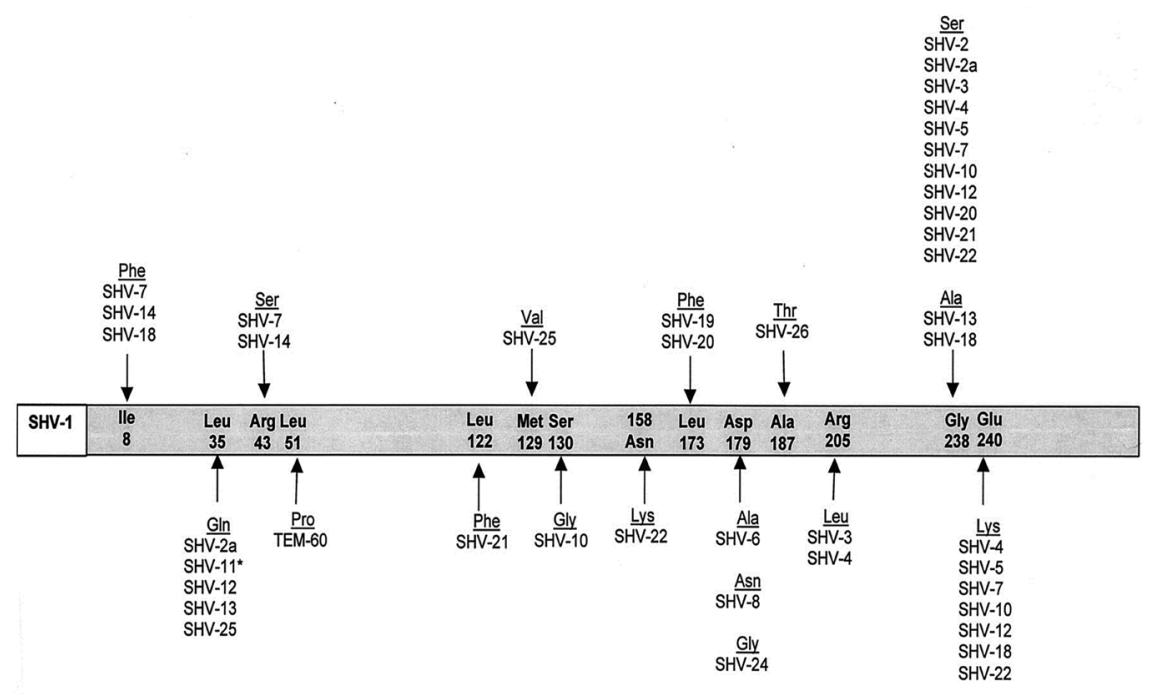

Figure 4. Depicts the amino acid substitutions in the different SHV variants in comparison with SHV-1 adapted from Bradford (2001).

\subsubsection{CTX-M}

The designation CTX refers to the potent hydrolytic activity of these enzymes against cefotaxime. However, some CTX-M-types hydrolyze ceftazidime and also cefepime with high efficiency [11] [47] [48]. The hydrolytic activity of CTX-M is inhibited by $\beta$-lactamase inhibitors. Tazobactam exhibits 10 -fold greater inhibitory activity than clavulanic acid [39]. CTX-M-type $\beta$-lactamases are related to the chromosomal $\beta$-lactamase of Kluyvera sps. [49].

CTX-M $\beta$-lactamases are typical ES $\beta$ Ls that belong to Bush's group 2 be and Ambler's class A. There are at least 128 CTX-M types that have been described so far. bla CTX-M is a 291 amino acid encoding enzyme and the change in any one of them result in a new CTX-M variant [50]. By using amino-acid sequence relatedness, phylogeny tree of CTX-M $\beta$-lactamases has been constructed. They are divided into five clusters, namely CTX-M-1, CTX-M-2, CTX-M-8, CTX-M-9 and CTX-M-25 [41]. So far, the database availability for the 172 CTX-M variants shows distinct (http://www.lahey.org/Studies) with distinct amino acid sequence and functional characteristics.

Few members are shown below:

CTX-M-1 cluster: CTX-M-1, -3, -10, -12, -15, -22, -23

CTX-M-2 cluster: CTX-M-2, -4, -5, -6, -7, -20, -76, -77

CTX-M-8 cluster: CTX-M-8, $-40,-63$

CTX-M-9 cluster: CTX-M-9, $-14,-15,-16,-17,-18,-19$

CTX-M-25 cluster: CTX-M-25, -26, -39, -41, -91

\subsubsection{Oxa-Beta-Lactamase}

OXA name refers to the oxacillin-hydrolysing ability of these $\beta$-lactamases. They hydrolyze oxacillin and cloxacillin at a higher rate than $50 \%$ that of benzylpenicillin [39]. OXA- $\beta$-lactamases are mainly found in $P$. aeruginosa [51]. The most common OXA-type $\beta$-lactamase is OXA-1. It has been detected in up to $10 \%$ of 
E. coli isolates [52]. Most OXA-type $\beta$-lactamases do not hydrolyze the extended spectrum cephalosporin and hence are not regarded as ES $\beta$ Ls. OXA-ES $\beta$ Ls includes, OXA-10 (weak), -11, -14, -16, -17. -19, -15, -18, -28, -31, -32, -35 and -45 [11] [41]. Altogether, OXA type $\beta$-lactamases is explosively increasing based on the amino acid sequence variations and so far 498 variants have been reported and arranged in the database (http://www.lahey.org/Studies/other).

\subsubsection{Other ES $\beta$ L-Types}

It includes PER-1 (for Pseudomonas extended resistance), PER-2, VEB-1 (for Vietnamese extended spectrum), VEB-2, GES (Guiana-extended spectrum) and SFO (Serratia fonticola) which share only $25 \%$ and $27 \%$ homology with TEM and SHV types. It was observed that, PER-1 with $86 \%$ amino acid homology and PER-2 incidence was high in Turkey and South America respectively. VEB-1 and TLA-1 were discovered in E. coli clinical isolates from Vietnamese patient hospitalized in France and Mexico respectively [53]. PER-1, PER-2, VEB-1 and TLA-1 are related to Bacteroides sps. with reference to their homology to the chromosomal $\beta$-lactamase [53]. These novel enzymes are found infrequently and the details of these enzymes are reviewed elsewhere [42] [54].

\subsection{Inhibitors for $\mathrm{ES} \beta \mathrm{L}$}

The agent that inhibits $\beta$-lactamase enzymes by irreversible binding to its active site leads to permanent inactivation. The first clinically used $\beta$-lactamase inhibitor was clavulanic acid isolated from $S$. clavuligerus which exhibited weak antimicrobial activity. But, if combined with amoxicillin, it significantly increases the antimicrobial activity of the later. $\beta$-lactamase inhibitors are most effective against class-A $\beta$-lactamase including CTX-M, TEM and SHV-ES $\beta$ Ls [55].

\subsection{Epidemiology of ES $\beta$ LS}

$\mathrm{ES} \beta$ Ls are currently a universal problem in hospitalized patients as well as community settings. Prevalence of ES $\beta$ Ls among clinical isolates is variable with respect to different institutions, countries and continents [56]. Recent studies have shown a significant global increase in the ES $\beta \mathrm{L}$ rate. In North America the ES $\beta \mathrm{L}$ rate in Klebsiella sps., $E$. coli and $P$. mirabilis ranges from $4.2 \%-44 \%, 3.3 \%-$ 4.7\% and 3.1\% - 9.5\%, respectively. In Latin America, the ES $\beta \mathrm{L}$ rate of Klebsiella sps., E. coli and P. mirabilis lie in the ranges $40 \%-47.3 \%, 6.7 \%-25.4 \%$ and $9.5 \%$ - 35.5\%, respectively. In the Far East-Western Pacific area, the ES $\beta \mathrm{L}$ rate in Klebsiella sps., E. coli, Salmonella sps. and P. mirabilis ranges between $11.3 \%$ $51 \%, 7.9 \%-23.6 \%, 3.4 \%$ and $1.4 \%-1.8 \%$, respectively [57].

The highest rate was detected in Egypt and Greece $(38.5 \%$ and $27.4 \%$, respectively) and the lowest rate was in Netherlands and Germany (2\% and 2.6\%, respectively) according to the Pan European Antimicrobial Resistance Local Surveillance (PEARLS) study done between the years 2001-2002 [58]. However, in comparison to other countries in United States (US) the prevalence of ES $\beta \mathrm{L}$ encoding Enterobacteriaceae was around 3\%. A study reflects that lower ES $\beta \mathrm{L}$ 
prevalence in Northern European countries compared to South-Eastern European countries [53] [59]. Whereas in Spain, only 1.5\% among 1962 invasive $E$. coli isolates in 2001 were found to produce ES $\beta \mathrm{L}$ [60]. In contrary, France had $11.4 \% \mathrm{~K}$. pneumoniae and $47.7 \% \mathrm{E}$. aerogenes isolates were seen which produced ES $\beta \mathrm{L}$ in a surveillance covering many medical centres during 1996 to 2000 [61]. Northern European countries still have the lowest prevalence of ES $\beta$ Lproducing Enterobacteriaceae ranging from $<1 \%$ in the Netherlands to 3\% in Sweden.

It has been observed that ES $\beta$ L allele may be restricted to certain country or a certain geographical region, like blaTEM-10 that has been detected in the United States in several outbreaks for many years before the detection of this allele was found in Europe [62]. Another example demonstrated by blaTEM-3 which has not been detected in the United States but is been frequently observed in France [63]. In contrast, there are ES $\beta$ L alleles which are commonly encountered worldwide like SHV-5 and CTX-M-15 [53].

Travel plays an important role in the dissemination of antibiotic resistance [50]. The global dissemination of CTX-M-14 and CTX-M-15 producing/ST131 E. coli is attributed to the colonization or infection of travellers returning from high risk area like Indian subcontinent and the Middle East Asia confirming that returning travellers are most likely to acquire the predominant ES $\beta \mathrm{L}$-determinant in the visited country. Such acquisition can be achieved even without hospitalization or contact with the health care system in the visited country [64].

Several outbreaks have been reported, majority of which occurred in tertiary hospitals where the transfer of a colonized patient provide a chance for dissemination of the ES $\beta$ L-producing organism [65]. In a French Hospital, SHV-5 expressing $K$. pneumoniae were isolated from six peripartum women and two neonates. PFGE profiles of these strains indicated that all of the strains have PFGE-patterns identical to that of a strain isolated from contaminated ultrasonography coupling gel [66]. ES $\beta$ L-producing E. coli and K. pneumoniae having different PFGE-types, but carrying identical plasmid encoding TEM-10 have been isolated from many patients in different hospitals in Chicago. The occurrence of the same plasmid in the strains of different PFGE-genotypes is a clue for plasmid transfer [62] [67].

More interestingly, blaTEM-24 encoding, $180 \mathrm{~kb}$, conjugative plasmid was detected in four different enterobacterial species $E$. coli, $K$. pneumoniae, E. aerogenes and $P$. rettigeri isolated from the same patient suggesting horizontal transfer between the normal flora of the gut [68]. The findings of bla $a_{\mathrm{TEM}}$ were reported to be 75 percent among ES $\beta$ L-producing $K$. pneumoniae isolates [69] [16].

In India, reports have shown high rates of ES $\beta$ Ls since 1990s [70]. ES $\beta$ L producing Enterobacteriaceae are well established in the community were a study conducted showed $24 \%$ of ES $\beta \mathrm{L}$ producers and $74 \%$ and $76 \%$ had a history of prior use, at some time of a cephalosporin and quinolone, respectively [71]. 
Relatively very few genotyping studies have been carried out, SHV-12 in $K$. pneumoniae has been reported from Southern India to be linked to the qnrB plasmid-mediated quinolone resistance determinant, the first report being from S. marcescens [72] [73]. There is a report of SHV-5 produced by Salmonella Senftenberg causing an outbreak on a burns ward in Delhi [74]. The only genotype of a TEM ES $\beta$ L is TEM-104, reported in ten isolates of $K$. pneumoniae from New Delhi in 2001-2002 [75].

CTX-M-15 $\beta$-lactamase is now widely distributed across the world, but was first described in a small number of isolates from Delhi in 2000 [76]. A very recent survey from three widely dispersed centers in India showed that 95/130 cefpodoxime-resistant E. coli and K. pneumoniae isolates obtained between 2003 and 2005 carried a bla CTX-M gene, and when genotyped confirmed as blaCTXM-15 in all the cases [77]. The study by Ensor et al. (2006) prompted a letter reporting on isolates of Klebsiella spp. and E. coli collected in the late 1990s from six widely dispersed centers; 47 isolates were examined using PCR and DNA sequencing, and 37 were found to carry blaCTX-M-15, which was the only CTX-M genotype found [78]. CTX-M-15 was also identified from two of the $K$. pneumoniae isolates collected during 2002-2003 in Coimbatore, South India [72]. India, therefore, not only appears to have very high rates of ES $\beta \mathrm{L}$ production across the country, but is entirely dominated by blaCTX-M-15 gene.

Currently, the emergence and rapid dissemination of CTX-M positive ES $\beta \mathrm{L}$ producing bacteria have caused a change in ES $\beta$ L epidemiology [11] [79]. Furthermore, the recent identification of ES $\beta \mathrm{L}$ producing isolates that have acquired carbapenemases has further limited the therapeutic options available for treatment of these multidrug resistant microorganisms [16] [63].

The recognition of the importance of ES $\beta$ L's as a major mechanism of $\beta$-lactam resistance throughout the region came with presentation of data from the 1998-1999 SENTRY antimicrobial surveillance programme [80]. The incidence of ES $\beta \mathrm{L}$ production (no genotyping was undertaken) among $E$. coli isolates in the four Chinese sites varied from $13 \%$ to $35 \%$. In India, the rate of ES $\beta \mathrm{L}$ producers from pregnant women in E. coli isolates was 36.8\% [81]. Rates $>20 \%$ for the ES $\beta \mathrm{L}$ phenotype in $K$. pneumoniae in all participating mainland Chinese centers (one reaching 60\%), in one each of three Japanese and Taiwanese centers, and in the single Singapore center and Philippines center, were confirmed. Such high rates had previously been reported only from South America, in a follow-up study (1998-2002) lower rates were found in $K$. pneumoniae isolates from Australia and Japan $(<10 \%)$, but that in China was $30 \%$ and comparatively, low incidence rate in India have also been reported [81] [82]. The other area of Asia that is the Indian subcontinent high rates of ES $\beta \mathrm{L}$ production has been reported.

A number of other studies in India reported the incidence of ES $\beta \mathrm{L}$ producers to be $6.6 \%$ to $68 \%$. In south India, Subha et al. (2002) [83] reported $6.6 \% \mathrm{ES} \beta \mathrm{L}$ producers whereas Babypadmini et al. (2004) [84] reported 40.3\%. The ES $\beta \mathrm{L}$ 
production which was reported among Gram negative bacteria by Mathur et al. (2002) [85] was 68\% and Singhal, et al. (2005) [86] detected ES $\beta \mathrm{L}$ in $64 \%$ isolates and Rodrigues, et al. (2004) [87] reported 53\% ES $\beta$ L production. Other studies in India have also reported a very high prevalence of ES $\beta$ L producing Enterobacteriaceae. Accordingly, in North India about $46 \%$ of uropathogens belonging to Enterobacteriaceae were found to be ES $\beta \mathrm{L}$ producers [88].

Some reports have also described the molecular epidemiology of the ES $\beta \mathrm{L}$ producers [78]. One of the reasons contributing to the high prevalence of ES $\beta \mathrm{L}$ producers in India may be the crowded hospital conditions, including implementation of optimal hygienic practices, likely fueled by unrestricted use of antimicrobials without doctor's prescription [89]. A study reported that ES $\beta$ L producing Enterobacteriaceae families were responsible for the onset of community infections in India [71]. CTX-M-15 is known to be having a peculiar association with the community onset of E. coli and K. pneumoniae [16] [90] [91].

\section{Metallo Beta Lactamases ( $\mathrm{M} \beta \mathrm{L})$}

Metallo $\beta$-lactamase was first identified in 1966 as $\beta$-lactamase II (BcII) in Bacillus cereus, when the cephalosporinase activity was shown to be inhibited by metal chelators like EDTA [92]. The early reported M $\beta$ L determinants were located on the chromosome and were produced by organisms of minor clinical relevance, e.g. Flavobacterium odoratum, B. cereus, and Legionella gormanii, that were regarded as rare curiosities [93].

The first report of transferable $\mathrm{M} \beta \mathrm{L}$ was recorded in $P$. aeruginosa from Japan in 1991 [94] and then on $\mathrm{M} \beta$ Ls were discovered with more clinically relevant genera such as Serratia, Bacteroides, and Pseudomonas [93]. The class B $\beta$-lactamases exhibit resistance to commercially available $\beta$ lactamase inhibitors, but are inhibited by metal ion chelators, such as EDTA. This class of enzymes is of particular interest and concern owing to the ability to hydrolyze and thus provide resistance to virtually all classes of $\beta$-lactams, including the carbapenems. A number of clinical Burkholderia cepacia isolates producing an inducible metalloenzymes (PCM-I) that also shows preferential hydrolysis of carbapenems/ imipenem have also been described [95]. A limited number of $B$. fragilis isolates have been shown to produce a chromosomal metalloenzyme, CfiA/CcrA that provides resistance to imipenem [96].

\subsection{Classification of $M \beta L S$}

$\mathrm{M} \beta \mathrm{L}$ s are a group of clinically important hydrolytic enzymes belonging to the molecular class B $\beta$-lactamases or group 3 according to the Bush-Jacoby-Medeiros functional classification [39]. These enzymes are about 250 amino acid residues in length [97] and require divalent cation(s), usually Zinc, for their hydrolysing activities [93] [95]. M $\beta$ Ls act on carbon nitrogen bond of $\beta$-lactam ring [97], but they are mechanically different from other $\beta$-lactamases, which have serine at the active site [93]. Some of these require only one Zinc ion per mole- 
cule, while others require two Zinc ions per molecule (a binuclear active site) [97]. The metal ion(s) at the active site enables them to hydrolyze broad spectrum $\beta$-lactam agents including carbapenems, but their ability can be inhibited by metal ion chelators, such as EDTA, 1,10-o-phenanthroline, and mercapto compounds [95].

$\mathrm{M} \beta \mathrm{Ls}$ are generally encoded by genes carried on mobile genetic elements, such as plasmids, transposons, and integrons [94] [98]. General characteristics of IMP type M $\beta$ Ls were capable to hydrolyze carbapenems, but not monobactam. In fact, the blaIMP genes were often mediated by integrons, where aminoglycoside acetyl transferase and dihydropteroate synthetase genes also co-exist [99] [100].

\subsubsection{Types of $M \beta L$}

Currently, 21 variants of IMP type M $\beta$ Ls have been reported in the clinical isolates of Enterobacteriaceae, Pseudomonadaceae, and other non-fastidious Gramnegative non-fermenters. These $\mathrm{M} \beta \mathrm{L}$ includes, IMP-1 from Japan, Singapore, and the United Kingdom [101] [102] [103]; IMP-2, IMP-12, and IMP-13 from Italy [100] [104] [105]; IMP-3, IMP-6, and IMP-10 from Japan [106] [107] [108]; IMP-4 from Hong Kong and China [109] [110]; IMP-5 from Portugal [111]; IMP-7 from Canada and Malaysia [112] [113]; IMP-8 from Taiwan [92]; IMP-9 from China (accession no: AY033653), IMP-11 from Japan (accession no: AB074437); IMP-14 and IMP-15 from Thailand (accession no: AY553332 and AY553333, respectively); IMP-16 from Brazil (accession no: AJ584652); IMP-18 from United States of America (accession no: AY780674); IMP-19, IMP-20, and IMP-21 from Japan (accession no: AB184977, AB196988, and AB204557, respectively).

\subsection{Inhibitors for $M \beta L$}

Currently there are no clinically validated inhibitors of $M \beta L$ s are available. Inhibitors that covalently modify $\mathrm{M} \beta \mathrm{L}$ s include small thiol modifying reagents, such as mercuric (II) salts, p-chloromercuribenzoate [114], iodoacetic acid and mercaptoacetic acid thiol esters [115]. Inhibitors that chelate the active site of Zinc include EDTA, 1, 10- $o$-phenanthroline, dipicolinic acid, two phenazines from Streptomyces sps. [116], bis (1-N-tetrazol-5-yl) amine [117] and EDTA. More promising compounds are those which reversibly block the active site by competitive inhibition, since these offers the potential for modification of the structure to improve the specificity of the inhibitor for $\mathrm{M} \beta \mathrm{L}$ s alone. Such compounds include biphenyl tetrazoles [117], mercaptophenyl acetic acid derivatives, which do not covalently modify the enzyme (probably because the phenyl ring sterically hinders the hydrolysis of the carbonyl thiol bond) [115], trifluoro methyl alcohols and ketones [118], N-(2'-mercaptoethyl)-2-phenylacetamide [119], thiomandelic acid [120], D- and L-captopril inhibitors [121], 6-(mercaptomethyl) and penicillinases [122]. 


\subsection{Epidemiology of $M \beta L$}

During the past decade, both the global dimension of this problem and an unanticipated diversity of enzymes have been revealed, as acquired $\mathrm{M} \beta \mathrm{L}$ s have been detected in clinical isolates from Asia as well as from Europe, North and South America [92] [100] [109] [112] [123]. Currently, the most prevalent and widespread acquired $\mathrm{M} \beta \mathrm{L}$ s are the IMP-type and VIM type enzymes, of which several variants are known. Other types of acquired M $\beta$ Ls SPM-1, GIM-1, and SIM-1 have also been identified [98] [124].

Peleg and his colleagues (2005) for the first time reported the emergence and rapid dissemination of an acquired $M \beta L$ determinant in a hospital setting in Australia, a continental resistance [125]. The $\mathrm{M} \beta \mathrm{L}$ gene involved in the outbreak was blaIMP-4, an allelic variant of blaIMP-1 gene previously identified in clinical isolates of Acinetobacter sps. and Citrobacter youngae from Hong Kong and the People's Republic of China [109] [110]. It was likely imported to Australia from those areas via international travelers and following the first detection in $P$. aeruginosa, the $\mathrm{M} \beta \mathrm{L}$ gene was found in hospital acquired isolates of Gram-negative pathogens of 5 different species, including $P$. aeruginosa, $K$. pneumoniae, Serratia marcescens, Enterobacter cloacae, and E. coli. This is the first report for a rapid emergence in a single hospital of the same acquired $M \beta L$ determinant in several different species, as well as in different strains of the same species (clonal diversity was observed among the $\mathrm{M} \beta \mathrm{L}$ positive isolates of $K$. pneumoniae and $S$. marcescens) [125]. In fact, $\mathrm{M} \beta \mathrm{L}$ producers usually exhibit complex MDR phenotypes because of their nosocomial origin and because of the frequent links between $\mathrm{M} \beta \mathrm{L}$ genes and other resistance genes on the mobile DNA elements that are involved in their dissemination [126].

Only a low number of $\mathrm{M} \beta \mathrm{L}$ producing isolates appeared to be carbapenem resistant [125] [127]. It is known that, unlike $P$. aeruginosa and Acinetobacter species, members of Enterobacteriaceae with acquired $\mathrm{M} \beta \mathrm{L}$ genes tend to exhibit carbapenem MICs that remain lower than the breakpoint for resistance, unless permeability is also impaired [126]. This phenomenon has major implications for the detection of similar isolates (and consequently for surveillance) and also for the selection of antimicrobial chemotherapy.

\section{Classification Based on Sequence Similarities by Hidden Markov Models (HMM) for $\beta$-Lactamase Annotation}

Most widely used classification scheme for BLs is the Ambler structural classification, which is based on sequence similarity and it's still the best currently used. It classifies the BLs into 4 classes: the classes $\mathrm{A}, \mathrm{C}$, and $\mathrm{D}$ of serine- $\beta$-lactamases (SBLs) and the Class B of metallo- $\beta$-lactamases (M $\beta$ Ls), where Class B is further divided into subclasses B1, B2, and B3, using sequence conservation data [27] [128] [129]. Even though SBLs and MBLs are able to break amide and ester bonds they do not belong to a common ancestor due to 2 distinct protein superfamilies [130]. SBL's tertiary structures are similar enough among themselves to 
be homologous [131] while, the differences lie between their primary structures and catalytic mechanisms that divide them into classes A, C, and D [132].

The 3 subclasses of MBL, B1 and B2 have detectable sequence similarity and a common ancestor between them but not with B3 [133] [134]. The scheme proposed by Hall and Barlow (2005), based on structural information the former subclasses B1 and B2 were merged and renamed as class $\mathrm{MB}$, whereas subclass $\mathrm{B} 3$ was renamed as class ME. Thus, the $5 \mathrm{BL}$ classes which are considered as third classification level namely, SA, SC, SD, MB, and ME with subclasses MB1 and $\mathrm{MB} 2$ represent the fourth and last hierarchical level [132].

In few studies, phylogenetic and amino acid-based sequence similarities showed further division of classes SA and SD into 2 different new BL subclasses [35] [135]. Molecular classification of BLs does not represent currently to its actual sequence diversity and no precise definition for various classes and subclasses have been precised. Silveria et al. (2018) proposed new BL class with fused domains and extended action spectrum. This classification is based on a previous hierarchical scheme, profiles of Hidden Markov Models (HMM) and sequence clustering using similarity was proposed [136] that provides genomes in $\mathrm{BL}$ annotation and know the BLs distribution among bacteria phyla suggesting new BL subclasses.

\section{Conclusion}

Beta-lactamases producing bacteria causing nosocomial infections have resulted in a steep rise in their incidence in recent years. The scientific community reported extensively about the high morbidity-mortality rates due to these $\beta$-lactamases resistant MDR strains. Henceforth, detection of community and hospital transmission by $\beta$-lactamase pathogens becomes a paramount importance. Rapid identification of ES $\beta$ L pathogens and their antibiotic resistance patterns will help the clinicians to select appropriate drug regimens like combination therapy and reduce their further spread. Since the epidemiology of ES $\beta \mathrm{L}$ and $\mathrm{M} \beta \mathrm{L}$ producing bacteria is becoming more complex in both hospitals and community, it is important to regulate and monitor MDR among clinical isolates. "Super bug", bacteria might evolve in the near coming future for relatively all the antibiotics if we are not cautious in handling them. This alarms the development and spreading of the disease globally and incapability to cure the infection, and ultimately leading to mortality or death. In this situation, a constant monitoring, dispense of antibiotics for non-emergency cases only on the clinical reports and careful worldwide surveillance is urgently warranted.

\section{Conflicts of Interest}

The authors declare no conflicts of interest regarding the publication of this paper.

\section{References}

[1] Saunders, W. (2011) Dorland's Illustrated Medical Dictionary, 2007. Saunders El- 
sevier, Philadelphia.

[2] Alekshun, M.N. and Levy, S.B. (2007) Molecular Mechanisms of Antibacterial Multidrug Resistance. Cell, 128, 1037-1050. https://doi.org/10.1016/j.cell.2007.03.004

[3] Watanabe, T. (1963) Infective Heredity of Multiple Drug Resistance in Bacteria. Microbiology and Molecular Biology Reviews, 27, 87-115. https://doi.org/10.1128/BR.27.1.87-115.1963

[4] Leplae, R., Lima-Mendez, G. and Toussaint, A. (2006) A First Global Analysis of Plasmid Encoded Proteins in the ACLAME Database. FEMS Microbiology Reviews, 30, 980-994. https://doi.org/10.1111/j.1574-6976.2006.00044.x

[5] Shaikh, S., Fatima, J., Shakil, S., Rizvi, S.M. and Kamal, M.A. (2015) Antibiotic Resistance and Extended Spectrum Beta-Lactamases: Types, Epidemiology and Treatment. Saudi Journal of Biological Sciences, 22, 90-101. https://doi.org/10.1016/j.sjbs.2014.08.002

[6] Steward, C.D., Wallace, D., Hubert, S.K., Lawton, R., Fridkin, S.K., Gaynes, R.P., McGowan Jr., J.E. and Tenover, F.C. (2000) Ability of Laboratories to Detect Emerging Antimicrobial Resistance in Nosocomial Pathogens: A Survey of Project ICARE Laboratories. Diagnostic Microbiology and Infectious Disease, 38, 59-67. https://doi.org/10.1016/S0732-8893(00)00161-9

[7] Sharma, M., Pathak, S. and Shrivastava, P. (2013) Prevalence and Antibiogram of Extended Spectrum b-Lactamase (ESBL) Producing Gram Negative Bacilli and Further Molecular Characterization of ESBL Producing Escherichia coli and Klebsiella spp. Journal of Clinical and Diagnostic Research, 7, 2168-2172.

[8] Mirza, S., Jadhav, S., Misra, R.N. and Das, N.K. (2019) Coexistence of $\beta$-Lactamases in Community-Acquired Infections in a Tertiary Care Hospital in India. International Journal of Microbiology, 2019, Article ID: 7019578. https://doi.org/10.1155/2019/7019578

[9] Bush, K. and Jacoby, G.A. (2010) Updated Functional Classification of $\beta$-Lactamases. Antimicrobial Agents and Chemotherapy, 54, 969-976. https://doi.org/10.1128/AAC.01009-09

[10] Pitout, J.D.D. (2010) Infections with Extended Spectrum Beta Lactamase-Producing Enterobacteriaceae: Changing Epidemiology and Drug Treatment Choices. Drugs, 70, 313-333. https://doi.org/10.2165/11533040-000000000-00000

[11] Paterson, D.L. and Bonomo, R.A. (2005) Extended-Spectrum $\beta$-Lactamases: A Clinical Update. Clinical Microbiology Reviews, 18, 657-686.

https://doi.org/10.1128/CMR.18.4.657-686.2005

[12] De Araújo Viana Marques, D., Machado, S.E.F., Ebinuma, V.C.S., De Albuquerque Lima Duarte, C., Converti, A. and Porto, A.L.F. (2018) Production of $\beta$-Lactamase Inhibitors by Streptomyces Species. Antibiotics, 7, 61. https://doi.org/10.3390/antibiotics7030061

[13] Hawkey, P. and Finch, R. (2007) Tigecycline: In-Vitro Performance as a Predictor of Clinical Efficacy. Clinical Microbiology and Infection, 13, 354-362. https://doi.org/10.1111/j.1469-0691.2006.01621.x

[14] Walsh, T.R. (2008) Clinically Significant Carbapenemases: An Update. Current Opinion in Infectious Diseases, 21, 367-371. https://doi.org/10.1097/QCO.0b013e328303670b

[15] Mena, A., Plasencia, V., Garcia, L., Hidalgo, O., Ayestaran, J.I., Alberti, S., Borrell, N., Perez, J.L. and Oliver, A. (2006) Characterization of a Large Outbreak by CTXM-1-Producing Klebsiella pneumoniae and Mechanisms Leading to in Vivo Carba- 
penem Resistance Development. Journal of Clinical Microbiology, 44, 2831- 2837. https://doi.org/10.1128/JCM.00418-06

[16] Gautam, V., Thakur, A., Sharma, M., Singh, A., Bansal, S., Sharma, A., Kapil, A., Das, B.K., Sistla, S., Parija, S.C., Veeraraghavan, B., Prakash, J.A.J., Walia, K., Ohri, V.C. and Ray, P. (2019) Molecular Characterization of Extended-Spectrum $\beta$-Lactamases among Clinical Isolates of Escherichia coli and Klebsiella pneumoniae: A MultiCentric Study from Tertiary Care Hospitals in India. Indian Journal of Medical Research, 149, 208-215. https://doi.org/10.4103/ijmr.IJMR 17218

[17] Grover, S.S., Doda, A., Gupta, N., Gandhoke, I., Batra, J., Hans, C. and Khare, S. (2017) New Delhi Metallo- $\beta$-Lactamase-Type Carbapenemases Producing Escherichia coli Isolates from Hospitalized Patients: A Pilot Study. Indian Journal of Medical Research, 146, 105-110. https://doi.org/10.4103/ijmr.IJMR 59415

[18] Hall, B.G. and Barlow, M. (2004) Evolution of the Serine $\beta$-Lactamases: Past, Present and Future. Drug Resistance Updates, 7, 111-123.

https://doi.org/10.1016/j.drup.2004.02.003

[19] Poole, K. (2004) Resistance to $\beta$-Lactam Antibiotics. Cellular and Molecular Life Sciences, 61, 2200-2223. https://doi.org/10.1007/s00018-004-4060-9

[20] Marcade, G., Deschamps, C., Boyd, A., Gautier, V., Picard, B., Branger, C., Denamur, E. and Arlet, G. (2009) Replicon Typing of Plasmids in Escherichia coli Producing Extended-Spectrum $\beta$-Lactamases. Journal of Antimicrobial Chemotherapy, 63, 67-71. https://doi.org/10.1093/jac/dkn428

[21] Bauernfeind, A., Grimm, H. and Schweighart, S. (1990) A New Plasmidic Cefotaximase in a Clinical Isolate of Escherichia coli. Infection, 18, 294-298. https://doi.org/10.1007/BF01647010

[22] Alsterlund, R., Axelsson, C. and Olsson-Liljequist, B. (2012) Long-Term Carriage of Extended-Spectrum Beta-Lactamase-Producing Escherichia coli. Scandinavian Journal of Infectious Diseases, 44, 51-54. https://doi.org/10.3109/00365548.2011.592987

[23] Jostins, L., Ripke, S., Weersma R.K., et al. (2012) Host-Microbe Interactions Have Shaped the Genetic Architecture of Inflammatory Bowel Disease. Nature, 491, 119-124. https://doi.org/10.1038/nature11582

[24] Garau, G., Bebrone, C., Anne, C., Galleni, M., Frere, J. and Dideberg, O. (2005) A Metallo-Beta-Lactamase Enzyme in Action: Crystal Structures of the Monozinc carbapenemases CphA and Its Complex with Biapenem. Journal of Molecular Biology, 345, 785-795. https://doi.org/10.1016/j.jmb.2004.10.070

[25] Golemi-Kotra, D., Meroueh, S., Kim, C., Vakulenko, S., Bulychev, A., Stemmler, A, Stemmler, T. and Mobasherry. (2004) The Importance of a Critical Protonation State and the Fate of the Catalytic Steps in Class A Beta-Lactamases and Penicillin-Binding Proteins. Journal of Biological Chemistry, 279, 34665-34673. https://doi.org/10.1074/jbc.M313143200

[26] Meroueh, S.O., Fisher, J.F., Schlegel, H.B. and Mobashery, S. (2005) Ab Initio QM/MM Study of Class A Beta-Lactamase Acylation: Dual Participation of Glu166 and Lys73 in a Concerted Base Promotion of Ser70. Journal of the American Chemical Society, 127, 15397-15407. https://doi.org/10.1021/ja051592u

[27] Ambler, R.P. (1980) The Structure of Beta-Lactamases. Philosophical Transactions of the Royal Society B: Biological Sciences, 289, 321-331.

https://doi.org/10.1098/rstb.1980.0049

[28] Matagne, A., Lamotte-Brasseur, J. and Frere, J.M. (1998) Catalytic Properties of Class A-Lactamases: Efficiency and Diversity. Biochemical Journal, 330, 581-598. 
https://doi.org/10.1042/bj3300581

[29] Ambler, R.P., Coulson, A.F., Frere, J.M., Ghuysen, J.M., Joris, B., Forsman, M., Levesque, R.C., Tiraby, G. and Waley, S.G. (1991) A Standard Numbering Scheme for the Class A Beta-Lactamases. Biochemical Journal, 276, 269-270. https://doi.org/10.1042/bj2760269

[30] Risso, V.A., Gavira, J.A., Mejia-Carmona, D.F., Gaucher, E.A. and Sanchez-Ruiz, J.M. (2013) Hyperstability and Substrate Promiscuity in Laboratory Resurrections of Precambrian $\beta$-Lactamases. Journal of the American Chemical Society, 135, 2899-2902. https://doi.org/10.1021/ja311630a

[31] Tranier, S., Bouthors, A.T., Maveyraud, L., Guillet, V., Sougakoff, W. and Samama, J.P. (2000) The High Resolution Crystal Structure for Class A $\beta$-Lactamase PER-1 Reveals the Bases for Its Increase in Breadth of Activity. Journal of Biological Chemistry, 275, 28075-28082. https://doi.org/10.1074/jbc.M003802200

[32] Ruggiero, M., Kerff, F., Herman, R., Sapunaric, F., Galleni, M., Gutkind, G., Charlier, P., Sauvage, E. and Power, P. (2014) Crystal Structure of the Extendedspectrum $\beta$-Lactamase PER-2 and Insights into the Role of Specific Residues in the Interaction with $\beta$-Lactams and $\beta$-Lactamase Inhibitors. Antimicrobial Agents and Chemotherapy, 58, 5994-6002. https://doi.org/10.1128/AAC.00089-14

[33] Wang, F., Cassidy, C. and Sacchettini, J.C. (2006) Crystal Structure and Activity Studies of the Mycobacterium tuberculosis Beta-Lactamase Reveal Its Critical Role in Resistance to Beta-Lactam Antibiotics. Antimicrobial Agents and Chemotherapy, 50, 2762-2771. https://doi.org/10.1128/AAC.00320-06

[34] Ke, W., Bethel, C.R., Papp-Wallace, K.M., Pagadala, S.R., Nottingham, M., Fernandez, D., Buynak, J.D., Bonomo, R.A. and van den Akker, F. (2012) Crystal Structures of KPC-2 $\beta$-Lactamase in Complex with 3-Nitrophenyl Boronic Acid and the Penam Sulfone PSR-3-226. Antimicrobial Agents and Chemotherapy, 56, 2713-2718. https://doi.org/10.1128/AAC.06099-11

[35] Philippon, A., Slama, P., Deny, P. and Labia, R. (2016) A Structure-Based Classification of Class A $\beta$-Lactamases, a Broadly Diverse Family of Enzymes. Clinical Microbiology Reviews, 29, 29-57. https://doi.org/10.1128/CMR.00019-15

[36] Livermore, D.M. (2008) Defining an Extended-Spectrum $\beta$-Lactamase. Clinical Microbiology and Infection, 4, 3-10. https://doi.org/10.1111/j.1469-0691.2007.01857.x

[37] McDanel, J., Schweizer, M., Crabb, V., Nelson, R., Samore, M., Khader, K., Blevins, A.E., Diekema, D., Chiang, H., Nair, R. and Perencevich, E. (2017) Incidence of Extended-Spectrum $\beta$-Lactamase (ESBL)-Producing Escherichia coli and Klebsiella Infections in the United States: A Systematic Literature Review. Infection Control \& Hospital Epidemiology, 38, 1209-1215. https://doi.org/10.1017/ice.2017.156

[38] Murray, T.S. and Peaper, D.R. (2015) The Contribution of Extended-Spectrum $\beta$ Lactamases to Multidrug-Resistant Infections in Children. Current Opinion in Pediatrics, 27, 124-131. https://doi.org/10.1097/MOP.0000000000000182

[39] Bush, K., Jacoby, G.A. and Medeiros, A.A. (1995) A Functional Classification Scheme for $\beta$-Lactamases and Its Correlation with Molecular Structure. Antimicrobial Agents and Chemotherapy, 39, 1211-1233.

https://doi.org/10.1128/AAC.39.6.1211

[40] Datta, N. and Kontomichalou, P. (1965) Penicillinase Synthesis Controlled by Infectious R Factors in Enterobacteriaceae. Nature, 208, 239-241.

https://doi.org/10.1038/208239a0

[41] Rahman, S., Ali, T., Ali, I., Khan, N.A., Han, B. and Gao, J. (2018) The Growing 
Genetic and Functional Diversity of Extended Spectrum Beta-Lactamases. BioMed Research International, 2018, Article ID: 9519718. https://doi.org/10.1155/2018/9519718

[42] Jacoby, G.A. (1997) Extended-Spectrum $\beta$-Lactamases and Other Enzymes Providing Resistance to Oxyimino- $\beta$-Lactams. Infectious Disease Clinics of North America, 11, 875-887. https://doi.org/10.1016/S0891-5520(05)70395-0

[43] Sykes, R.B. and Bush, K. (1982) Physiology, Biochemistry, and Inactivation of $\beta$ Lactamases. In: Morin, R.B. and Gorman, M., Eds., The Biology of Beta-Lactam Antibiotics, Vol. 3, Academic Press, Waltham, 155-207. https://doi.org/10.1016/B978-0-12-506303-6.50008-X

[44] Knothe, H., Shah, P., Krcmery, V., Antal, M. and Mitsuhashi, S. (1983) Transferable Resistance to Cefotaxime, Cefoxitin, Cefamandole and Cefuroxime in Clinical Isolates of Klebsiella pneumoniae and Serratia marcescens. Infection, 11, 315-317. https://doi.org/10.1007/BF01641355

[45] Paterson, D.L., Hujer, K.M., Hujer, A.M., Yeiser, B., Bonomo, M.D., Rice, L.B. and Bonomo, R.A. (2003) Extended-Spectrum $\beta$-Lactamases in Klebsiella pneumoniae Bloodstream Isolates from Seven Countries: Dominance and Widespread Prevalence of SHV- and CTX-M-Type $\beta$-Lactamases. Antimicrobial Agents and Chemotherapy, 47, 3554-3560. https://doi.org/10.1128/AAC.47.11.3554-3560.2003

[46] Perilli, M., Segatore, B., Mugnaioli, C., Celenza, G., Rossolini, G.M., Stefani, S., Luzzaro, F., Pini, B. and Amicosante, G. (2011) Persistence of TEM-52/TEM-92 and SHV-12 Extended-Spectrum Beta-Lactamases in Clinical Isolates of Enterobacteriaceae in Italy. Microbial Drug Resistance, 17, 521-524. https://doi.org/10.1089/mdr.2011.0059

[47] Baraniak, A., Fiett, J., Hryniewicz, W., Nordmann, P. and Gniadkowski, M. (2002) Ceftazidime-Hydrolysing CTX-M-15 Extended-Spectrum $\beta$-Lactamase (ESBL) in Poland. Journal of Antimicrobial Chemotherapy, 50, 393-396.

https://doi.org/10.1093/jac/dkf151

[48] Yu, W.L., Pfaller, M.A., Winokur, P.L. and Jones, R.N. (2002) Cefepime MIC as a Predictor of the Extended-Spectrum $\beta$-Lactamase Type in Klebsiella pneumoniae, Taiwan. Emerging Infectious Diseases, 8, 522-524. https://dx.doi.org/10.3201/eid0805.010346

[49] Decousser, J.W., Poirel, L. and Nordmann, P. (2001) Characterization of a Chromosomally Encoded Extended-Spectrum Class A $\beta$-Lactamase from Kluyvera cryocrescens. Antimicrobial Agents and Chemotherapy, 45, 3595-3598.

https://doi.org/10.1128/AAC.45.12.3595-3598.2001

[50] Naseer, U. and Sundsfjord, A. (2011) The CTX-M Conundrum: Dissemination of Plasmids and Escherichia coli Clones. Microbial Drug Resistance, 17, 83-97. https://doi.org/10.1089/mdr.2010.0132

[51] Weldhagen, G.F., Poirel, L. and Nordmann, P. (2003) Ambler Class A ExtendedSpectrum $\beta$-Lactamases in Pseudomonas aeruginosa: Novel Developments and Clinical Impact. Antimicrobial Agents and Chemotherapy, 47, 2385-2392. https://doi.org/10.1128/AAC.47.8.2385-2392.2003

[52] Livermore, D.M. (1995) Beta-Lactamases in Laboratory and Clinical Resistance. Clinical Microbiology Reviews, 8, 557-584. https://doi.org/10.1128/CMR.8.4.557

[53] Bradford, P.A. (2001) Extended-Spectrum $\beta$-Lactamases in the 21st Century: Characterization, Epidemiology, and Detection of This Important Resistance Threat. Clinical Microbiology Reviews, 14, 933-951. https://doi.org/10.1128/CMR.14.4.933-951.2001 
[54] Naas, T., Poirel, L. and Nordmann, P. (2008) Minor Extended-Spectrum $\beta$-Lactamases. Clinical Microbiology and Infection, 14, 42-52. https://doi.org/10.1111/j.1469-0691.2007.01861.x

[55] Drawz, S.M. and Bonomo, R.A. (2010) Three Decades of Beta-Lactamase Inhibitors. Clinical Microbiology Reviews, 23, 160-201. https://doi.org/10.1128/CMR.00037-09

[56] Al Jasser, A.M. (2006) Extended-Spectrum Beta-Lactamase (ESBLS): A Global Problem. Kuwait Medical Journal, 38, 171-185.

[57] Sturenburg, E., and Mack, D. (2003) Extended-Spectrum $\beta$-Lactamases: Implications for the Clinical Microbiology Laboratory, Therapy, and Infection Control. Journal of Infection, 47, 273-295. https://doi.org/10.1016/S0163-4453(03)00096-3

[58] Bouchillon, S.K., Johnson, B.M., Hoban, D.J., Johnson, J.L., Dowzicky, M.J., Wu, D.H., Visalli, M.A. and Bradford, P.A. (2004) Determining Incidence of Extended Spectrum $\beta$-Lactamase Producing Enterobacteriaceae, Vancomycin-Resistant Enterococcus faecium and Methicillin-Resistant Staphylococcus aureus in 38 Centers from 17 Countries: The PEARLS Study 2001-2002. International Journal of Antimicrobial Agents, 24, 119-124. https://doi.org/10.1016/j.ijantimicag.2004.01.010

[59] Coque, T.M., Baquero, F., and Canton, R. (2008) Increasing Prevalence of ESBLProducing Enterobacteriaceae in Europe. Eurosurveillance, 13, Article ID: 19044.

[60] Oteo, J., Campos, J. and Baquero, F. (2002) Antibiotic Resistance in 1962 Invasive Isolates of Escherichia coli in 27 Spanish Hospitals Participating in the European Antimicrobial Resistance Surveillance System (2001). Journal of Antimicrobial Chemotherapy, 50, 945-952. https://doi.org/10.1093/jac/dkf255

[61] Albertini, M.T., Benoit, C., Berardi, L., Berrouane, Y., Boisivon, A., Cahen, P., Cattoen, C., Costa, Y., Darchis, P., Deliere, E., Demontrond, D., et al. (2002) Surveillance of Methicillin-Resistant Staphylococcus aureus (MRSA) and Enterobacteriaceae Producing Extended-Spectrum Beta-Lactamase (ESBLE) in Northern France: A Five-Year Multicentre Incidence Study. The Journal of Hospital Infection, 52, $107-$ 113. https://doi.org/10.1053/jhin.2002.1286

[62] Bradford, P.A., Cherubin, C.E., Idemyor, V., Rasmussen, B.A. and Bush, K. (1994) Multiple Resistant Klebsiella pneumoniae Strains from Two Chicago Hospitals: Identification of the Extended-Spectrum TEM-12 and TEM-10 Ceftazidime-Hy- drolyzing Beta-Lactamases in a Single Isolate. Antimicrobial Agents and Chemotherapy, 38, 761-766. https://doi.org/10.1053/jhin.2002.1286

[63] Nordmann, P., Poirel, L., Toleman, M.A. and Walsh, T.R. (2011) Does BroadSpectrum $\beta$-Lactam Resistance Due to NDM-1 Herald the End of the Antibiotic Era for Treatment of Infections Caused by Gram-Negative Bacteria? Journal of Antimicrobial Chemotherapy, 66, 689-692. https://doi.org/10.1093/jac/dkq520

[64] Pitout, J.D.D., Campbell, L., Church, D.L., Gregson, D.B. and Laupland, K.B. (2009) Molecular Characteristics of Travel-Related Extended-Spectrum- $\beta$-Lactamase- Producing Escherichia coli Isolates from the Calgary Health Region. Antimicrobial Agents and Chemotherapy, 53, 2539-2543.

https://doi.org/10.1128/AAC.00061-09

[65] Paterson, D.L., Singh, N., Rihs, J.D., Squier, C., Rihs, B.L. and Muder, R.R. (2001) Control of an Outbreak of Infection Due to Extended-Spectrum Beta-LactamaseProducing Escherichia coli in a Liver Transplantation Unit. Clinical Infectious Diseases, 33, 126-128. https://doi.org/10.1086/320882

[66] Gaillot, O., Maruejouls, C., Abachin, E., Lecuru, F., Arlet, G., Simonet, M. and Berche, P. (1998) Nosocomial Outbreak of Klebsiella pneumoniae Producing SHV-5 Extended-Spectrum $\beta$-Lactamase, Originating from a Contaminated Ultrasonogra- 
phy Coupling Gel. Journal of Clinical Microbiology, 36, 1357-1360. https://doi.org/10.1128/JCM.36.5.1357-1360.1998

[67] Wiener, J., Quinn, J.P., Bradford, P.A., Goering, R.V, Nathan, C., Bush, K., and Weinstein, R.A. (1999) Multiple Antibiotic-Resistant Klebsiella and Escherichia coli in Nursing Homes. JAMA, 281, 517-523.

https://doi.org/10.1001/jama.281.6.517

[68] Marchandin, H., Carriere, C., Sirot, D., Jean-Pierre, H. and Darbas, H. (1999) TEM-24 Produced by Four Different Species of Enterobacteriaceae, Including Providencia Rettgeri, in a Single Patient. Antimicrobial Agents and Chemotherapy, 43, 20692073. https://doi.org/10.1128/AAC.43.8.2069

[69] Jain, A. and Mondal, R. (2007) Prevalence \& Antimicrobial Resistance Pattern of Extended Spectrum Beta-Lactamase Producing Klebsiella spp Isolated from Cases of Neonatal Septicaemia. Indian Journal of Medical Research, 125, 89-94.

[70] Mathai, D., Rhomberg, P.R., Biedenbach, D.J. and Jones, R.N. (2002) Evaluation of the in Vitro Activity of Six Broad-Spectrum $\beta$-Lactam Antimicrobial Agents Tested against Recent Clinical Isolates from India: A Survey of Ten Medical Center Laboratories. Diagnostic Microbiology and Infectious Disease, 44, 367-377. https://doi.org/10.1016/S0732-8893(02)00466-2

[71] Gupta, V. and Datta, P. (2007) Extended-Spectrum Beta-Lactamases (ESBL) in Community Isolates from North India: Frequency and Predisposing Factors. International Journal of Infectious Diseases, 11, 88-89.

https://doi.org/10.1016/j.ijid.2006.02.002

[72] Jacoby, G.A., Walsh, K.E., Mills, D.M., Walker, V.J., Oh, H., Robicsek, A. and Hooper, D.C. (2006) $q n r B$, Another Plasmid-Mediated Gene for Quinolone Resistance. Antimicrobial Agents and Chemotherapy, 50, 1178-1182. https://doi.org/10.1128/AAC.50.4.1178-1182.2006

[73] Dhawan, B., Bonnet, R., Shukla, N.K., Mathur, P., Das, B.K. and Kapil, A. (2003) Infection with an Extended-Spectrum $\beta$-Lactamase-Producing Strain of Serratia marcescens Following Tongue Reconstruction. Journal of Clinical Microbiology, 41, 22332234. https://doi.org/10.1128/JCM.41.5.2233-2234.2003

[74] Revathi, G., Shannon, K.P., Stapleton, P.D., Jain, B.K., French, G.L. (1998) An Outbreak of Extended-Spectrum, $\beta$-Lactamase-Producing Salmonella senftenberg in a Burns Ward. Journal of Hospital Infection, 40, 295-302.

https://doi.org/10.1016/S0195-6701(98)90307-3

[75] Grover, S.S., Sharma, M., Chattopadhya, D., Kapoor, H., Pasha, S.T. and Singh G. (2006) Phenotypic and Genotypic Detection of ESBL Mediated Cephalosporin Resistance in Klebsiella pneumoniae: Emergence of High Resistance against Cefepime, the Fourth Generation Cephalosporin. Journal of Infection, 53, 279-288. https://doi.org/10.1016/j.jinf.2005.12.001

[76] Karim, A., Poirel, L., Nagarajan, S. and Nordmann, P. (2001) Plasmid-Mediated Extended-Spectrum $\beta$-Lactamase (CTX-M-3 Like) from India and Gene Association with Insertion Sequence ISEcp1. FEMS Microbiology Letters, 201, 237-241. https://doi.org/10.1111/j.1574-6968.2001.tb10762.x

[77] Ensor, V.M., Shahid, M., Evans, J.T. and Hawkey, P.M. (2006) Occurrence, Prevalence and Genetic Environment of CTX-M $\beta$-Lactamases in Enterobacteriaceae from Indian Hospitals. Journal of Antimicrobial Chemotherapy, 58, 1260-1263. https://doi.org/10.1093/jac/dkl422

[78] Walsh, T.R., Toleman, M.A. and Jones, R.N. (2007) Comment on: Occurrence, Prevalence and Genetic Environment of CTX-M $\beta$-Lactamases in Enterobacteria- 
ceae from Indian Hospitals. Journal of Antimicrobial Chemotherapy, 59, 799-800. https://doi.org/10.1093/jac/dk1532

[79] Pitout, J.D. and Laupland, K.B. (2008) Extended-Spectrum $\beta$-Lactamase-Producing Enterobacteriaceae: An Emerging Public-Health Concern. The Lancet Infectious Diseases, 8, 159-166. https://doi.org/10.1016/S1473-3099(08)70041-0

[80] Bell, J.M., Turnidge, J.D., Gales A.D., Pfaller, M.A., Jones, R.N., Sentry APAC Study Group. (2002) Prevalence of Extended Spectrum Beta-Lactamase (ESBL)-Producing Clinical Isolates in the Asia-Pacific Region and South Africa: Regional Results from SENTRY Antimicrobial Surveillance Program (1998-99). Diagnostic Microbiology and Infectious Disease, 42, 193-198. https://doi.org/10.1016/S0732-8893(01)00353-4

[81] Manjula, N.G, Math, G.C., Patil, S.A., Gaddad, S.M. and Shivannavar, C.T. (2014) Prevalence of MDR-ESBL Producing Escherichia coli Isolated from Urinary Tract Infections of Pregnant Women in Karnataka. Journal of Pure and Applied Microbiology, 8, 3765-3771.

[82] Hirakata, Y., Matsuda, J., Miyazaki, Y., Kamihira, S., Kawakami, S., Miyazawa, Y., Ono, Y., Nakazaki, N., Hirata, Y., Inoue, M., Turnidge, J.D., Bell, J.M., Jones, R.N., Kohno, S. and SENTRY Asia Pacific Participants (2005) Regional Variation in the Prevalence of Extended-Spectrum $\beta$-Lactamase-Producing Clinical Isolates in the Asia-Pacific Region (SENTRY 1998-2002). Diagnostic Microbiology and Infectious Disease, 52, 323-329. https://doi.org/10.1016/j.diagmicrobio.2005.04.004

[83] Subha, A. and Ananthan, S. (2002) Extended Spectrum Beta Lactamase (ESBL) Mediated Resistance to Third Generation Cephalosporins among Klebsiella pneumoniae in Chennai. Indian Journal of Medical Microbiology, 20, 92-95.

[84] Babypadmini, S. and Appalaraju, B. (2004) Extended Spectrum-Lactamases in Urinary Isolates of Escherichia coli and Klebsiella pneumoniae-Prevalence and Susceptibility Pattern in a Tertiary Care Hospital. Indian Journal of Medical Microbiology, 22, 172-174.

[85] Mathur, P., Kapil, A., Das, B. and Dhawan, B. (2005) Prevalence of Extended Spectrum Beta Lactamase Producing Gram Negative Bacteria in a Tertiary Care Hospital. Indian J Med Res, 115, 153-157.

[86] Singhal, S., Mathur, T., Khan, S., Upadhyay, D.J., Chugh, S., Gaind, R. and Rattan, A. (2005) Evaluation of Methods for AmpC Beta-Lactamase in Gram Negative Clinical Isolates from Tertiary Care Hospitals. Indian Journal of Medical Microbiology, 23, 120-124. https://doi.org/10.4103/0255-0857.16053

[87] Rodrigues, C., Joshi, P., Jani, S.H., Alphonse, M., Radhakrishnan, R. and Mehta, A. (2004) Detection of-Lactamases in Nosocomial Gram Negative Clinical Isolates. Indian Journal of Medical Microbiology, 22, 247-250.

[88] Akram, M., Shahid, M. and Khan, A. U. (2007) Etiology and Antibiotic Resistance Patterns of Community-Acquired Urinary Tract Infections in JNMC Hospital Aligarh, India. Annals of Clinical Microbiology and Antimicrobials, 6, Article ID: 4. https://doi.org/10.1186/1476-0711-6-4

[89] Ray, K., Mukhopadhyay, S., Dutt, D., Chatterjee, P.K., Roychowdhury, P.K., Roy, K. and Banerjee, S.N. (2003) Cross-Sectional Study of Consumption, Compliance and Awareness about Antibiotic Utilisation amongst the Urban Community in Kolkata. Journal of the Indian Medical Association, 101, 9-10.

[90] Nicolas-Chanoine, M.H., Blanco, J., Leflon-Guibout, V., Demarty, R., Alonso, M.P., Canica, M.M., Park, Y.J., Lavigne, J.P., Pitout, J. and Johnson, J.R. (2008) Intercontinental Emergence of Escherichia Coli Clone O25: H4-ST131 Producing CTXM-15. Journal of Antimicrobial Chemotherapy, 61, 273-281. 
https://doi.org/10.1093/jac/dkm464

[91] Muzaheed, D.Y., Adam-Haduch, J.M., Endimiani, A, Sidjabat, H.E., Gaddad, S.M. and Paterson, D.L. (2008) High Prevalence of CTX-M-15-Producing Klebsiella pneumoniae among Inpatients and Outpatients with Urinary Tract Infection in Southern India. Journal of Antimicrobial Chemotherapy, 61, 1393-1394.

https://doi.org/10.1093/jac/dkn109

[92] Yan, J.J., Ko, W.C. and Wu, J.J. (2001) Identification of a Plasmid Encoding SHV-12, TEM-1, and a Variant of IMP-2 Metallo- $\beta$-Lactamase, IMP-8, from a Clinical Isolate of Klebsiella pneumoniae. Antimicrobial Agents and Chemotherapy, 45, 2368-2371. https://doi.org/10.1128/AAC.45.8.2368-2371.2001

[93] Payne, D.J. (1993) Metallo- $\beta$-Lactamases-New Therapeutic Challenge. Journal of Medical Microbiology, 39, 93-99. https://doi.org/10.1099/00222615-39-2-93

[94] Murphy, T.A., Simm, A.M., Toleman, M.A., Jones, R.N. and Walsh, T.R. (2003) Biochemical Characterization of the Acquired Metallo- $\beta$-Lactamase SPM-1 from Pseudomonas aeruginosa. Antimicrobial Agents and Chemotherapy, 47, 582-587. https://doi.org/10.1128/AAC.47.2.582-587.2003

[95] Rasmussen, B.A. and Bush, K. (1997) Carbapenem-Hydrolyzing Beta-Lactamases. Antimicrobial Agents and Chemotherapy, 41, 223-232. https://doi.org/10.1128/AAC.41.2.223

[96] Kato, N., Yamazoe, K., Han, C.G. and Ohtsubo, E. (2003) New Insertion Sequence Elements in the Upstream Region of cfiA in Imipenem-Resistant Bacteroides fragilis Strains. Antimicrobial Agents and Chemotherapy, 47, 979-985.

https://doi.org/10.1128/AAC.47.3.979-985.2003

[97] Daiyasu, H., Osaka, K., Ishino, Y. and Toh, H. (2001) Expansion of the Zinc Metallo-Hydrolase Family of the $\beta$-Lactamase Fold. FEBS Letters, 503, 1-6. https://doi.org/10.1016/S0014-5793(01)02686-2

[98] Watanabe, M., Iyobe, S., Inoue, M. and Mitsuhashi, S. (1991) Transferable Imipenem Resistance in Pseudomonas aeruginosa. Antimicrobial Agents and Chemotherapy, 35, 147-151. https://doi.org/10.1128/AAC.35.1.147

[99] Livermore, D.M. (2001) Of Pseudomonas, Porins, Pumps and Carbapenems. Journal of Antimicrobial Chemotherapy, 47, 247-250. https://doi.org/10.1093/jac/47.3.247

[100] Toleman, M.A., Biedenbach, D., Bennett, D., Jones, R.N. and Walsh. T.R. (2003) Genetic Characterization of a Novel Metallo- $\beta$-Lactamase Gene, bla ${ }_{\mathrm{IMP}-13}$, Harboured by a Novel Tn5051-Type Transposon Disseminating Carbapenemase Genes in Europe: Report from the SENTRY Worldwide Antimicrobial Surveillance Programme. Journal of Antimicrobial Chemotherapy, 52, 583-590.

https://doi.org/10.1093/jac/dkg410

[101] Arakawa, Y., Murakami, M., Suzuki, K., Ito, H., Wacharotayankun, R., Ohsuka, S., Kato, N. and Ohta, M. (1995) A Novel Integron-Like Element Carrying the Metallo-Beta-Lactamase Gene blaIMP. Antimicrobial Agents and Chemotherapy, 39, 1612 1615. https://doi.org/10.1128/AAC.39.7.1612

[102] Koh, T.H., Sng, L.H., Babini, G.S., Woodford, N., Livermore, D.M. and Hall, L.M. (2001) Carbapenem-Resistant Klebsiella pneumoniae in Singapore Producing IMP-1 $\beta$-Lactamase and Lacking an Outer Membrane Protein. Antimicrobial Agents and Chemotherapy, 45, 1939-1940. https://doi.org/10.1128/AAC.45.6.1939-1940.2001

[103] Tysall, L., Stockdale, M.W., Chadwick, P.R., Palepou, M.F., Towner, K.J., Livermore, D.M. and Woodford, N. (2002) IMP-1 Carbapenemase Detected in an Acinetobac- 
ter Clinical Isolate from the UK. Journal of Antimicrobial Chemotherapy, 49, 217 218. https://doi.org/10.1093/jac/49.1.217

[104] Riccio, M.L., Franceschini, N., Boschi, L., Caravelli, B., Cornaglia, G., Fontana, R., Amicosante, G. and Rossolini, G.M. (2000) Characterization of the Metallo- $\beta$ - Lactamase Determinant of Acinetobacter baumannii AC-54/97 Reveals the Existence of blaimp Allelic Variants Carried by Gene Cassettes of Different Phylogeny. Antimicrobial Agents and Chemotherapy, 44, 1229-1235.

https://doi.org/10.1128/AAC.44.5.1229-1235.2000

[105] Docquier, J.D., Riccio, M.L., Mugnaioli, C., Luzzaro, F., Endimiani, A., Toniolo, A., Amicosante, G. and Rossolini, G.M. (2003) IMP-12, a New Plasmid-Encoded Metallo- $\beta$-Lactamase from a Pseudomonas Putida Clinical Isolate. Antimicrobial Agents and Chemotherapy, 47, 1522-1528.

https://doi.org/10.1128/AAC.47.5.1522-1528.2003

[106] Iyobe, S., Kusadokoro, H., Ozaki, J., Matsumura, N., Minami, S., Haruta, S., Sawai, T. and O'Hara, K. (2000) Amino Acid Substitutions in a Variant of IMP-1 Metallo-Lactamase. Antimicrobial Agents and Chemotherapy, 44, 2023-2027. https://doi.org/10.1128/AAC.44.8.2023-2027.2000

[107] Iyobe, S., Kusadokoro, H., Takahashi, A., Yomoda, S., Okubo, T., Nakamura, A. and O'Hara, K. (2002) Detection of a Variant Metallo- $\beta$-Lactamase, IMP-10, from Two Unrelated Strains of Pseudomonas aeruginosa and an Alcaligenes xylosoxidans Strain. Antimicrobial Agents and Chemotherapy, 46, 2014-2016. https://doi.org/10.1128/AAC.46.6.2014-2016.2002

[108] Yano, H., Kuga, A., Okamoto, R., Kitasato, H., Kobayashi, T. and Inoue, M. (2001) Plasmid-Encoded Metallo- $\beta$-Lactamase (IMP-6) Conferring Resistance to Carbapenems, Especially Meropenem. Antimicrobial Agents and Chemotherapy, 45, $1343-$ 1348. https://doi.org/10.1128/AAC.45.5.1343-1348.2001

[109] Chu, Y.W., Afzal-Shah, M., Houang, E.T., Palepou, M.F., Lyon, D.J., Woodford, N. and Livermore, D.M. (2001) IMP-4, a Novel Metallo- $\beta$-Lactamase from Nosocomial Acinetobacter spp. Collected in Hong Kong between 1994 and 1998. Antimicrobial Agents and Chemotherapy, 45, 710-714. https://doi.org/10.1128/AAC.45.3.710-714.2001

[110] Hawkey, P.M., Xiong, J., Ye, H., Li, H. and M’Zali, F.H. (2001) Occurrence of a New Metallo- $\beta$-Lactamase IMP-4 Carried on a Conjugative Plasmid in Citrobacter youngae from the People's Republic of China. FEMS Microbiology Letters, 194, 53-57.

[111] Da Silva, G.J., Correiam, M., Vital, C., Ribeiro, G., Sousa, J.C., Leitao, R., Peixe, L. and Duarte, A. (2002) Molecular Characterization of bla (IMP-5), a New Integron-Borne Metallo- $\beta$-Lactamase Gene from an Acinetobacter baumannii Nosocomial Isolate in Portugal. FEMS Microbiology Letters, 215, 33-39.

[112] Gibb, A.P., Tribuddharat, C., Moore, R.A., Louie. T.J., Krulicki, W., Livermore, D. M., Palepou, M.F. and Woodford, N. (2002) Nosocomial Outbreak of Carbapenem-Resistant Pseudomonas aeruginosa with a New blaımp Allele, bla ${ }_{\mathrm{IMP}}$-7. Antimicrobial Agents and Chemotherapy, 46, 255-258. https://doi.org/10.1128/AAC.46.1.255-258.2002

[113] Ho, S.E., Subramaniam, G., Palasubramaniam, S. and Navaratnam, P. (2002) Carbapenem-Resistant Pseudomonas aeruginosa in Malaysia Producing IMP-7 $\beta$-Lactamase. Antimicrobial Agents and Chemotherapy, 46, 3286-3287. https://doi.org/10.1128/AAC.46.10.3286-3287.2002

[114] Bush, K. and Singer, S.B. (1989) Biochemical Characteristics of Extended Broad Spectrum $\beta$-Lactamases. Infection, 17, 429-433. https://doi.org/10.1007/BF01645566 
[115] Payne, D.J., Bateson, J.H., Gasson, B.C., Proctor, D., Khushi, T., Farmer, T.H, Tolson, D.A., Bell, D., Skett, P.W., Marshall, A.C., Reid, R., Ghosez, L., Combret, Y. and Marchand-Brynaert, J. (1997) Inhibition of Metallo- $\beta$-Lactamases by a Series of Mercaptoacetic Acid Thiol Ester Derivatives. Antimicrobial Agents and Chemotherapy, 41, 135-140. https://doi.org/10.1128/AAC.41.1.135

[116] Gilpin, M.L., Fulston, M., Payne, D., Cramp, R. and Hood, I. (1995) Isolation and Structure Determination of Two Novel Phenazines from a Streptomyces with Inhibitory Activity against Metallo-Enzymes, Including Metallo- $\beta$-Lactamase. The Journal of Antibiotics, 48, 1081-1085. https://doi.org/10.7164/antibiotics.48.1081

[117] Toney, J.H., Fitzgerald, P.M., Grover-Sharma, N., Olson, S.H., May, W.J., Sundelof, J.G., Vanderwall, D.E., Cleary, K.A., Grant, S.K., Wu, J.K., Kozarich, J.W., Pompliano, D.L. and Hammond, G.G. (1998) Antibiotic Sensitization Using Biphenyl Tetrazoles as Potent Inhibitors of Bacteroides Fragilis Metallo- $\beta$-Lactamase. Chemistry \& Biology, 5, 185-196. https://doi.org/10.1016/S1074-5521(98)90632-9

[118] Walter, M.W., Felici, A., Galleni, M., Soto, R.P., Adlington, R.M., Baldwin, J.E., Frere, J.M., Gololobov, M. and Schofield, C.J. (1996) Trifluoromethyl Alcohol and Ketone Inhibitors of Metallo- $\beta$-Lactamases. Bioorganic \& Medicinal Chemistry Letters, 6, 2455-2458. https://doi.org/10.1016/0960-894X(96)00453-2

[119] Bounaga, S., Laws, A.P., Galleni, M. and Page, M.I. (1998) The Mechanism of Catalysis and the Inhibition of the Bacillus cereus Zinc-Dependent $\beta$-Lactamase. Biochemical Journal, 331, 703-711. https://doi.org/10.1042/bj3310703

[120] Mollard, C., Moali, C., Papamicael, C., Damblon, C., Vessilier, S., Amicosante, G., Schofield, C.J., Galleni, M., Frere, J.M. and Roberts. G. (2001) Theomandelic Acid, a Broad Spectrum Inhibitor of Zinc Beta-Lactamases. The Journal of Biological Chemistry, 276, 45015-45023. https://doi.org/10.1074/jbc.M107054200

[121] Antony, J., Gresh, N., Olsen, L., Hemmingsen, L., Schofield, C.J. and Bauer, R. (2002) Binding of D- and L-Captopril Inhibitors to Metallo- Beta Lactamase Studied by Polarizable Molecular Mechanics and Quantum Mechanics. Journal of Computational Chemistry, 23, 1281-1296. https://doi.org/10.1002/jcc.10111

[122] Buynak, J.D. (2004) The Discovery and Development of Modified Penicillin-and Cephalosporin-Derived $\beta$-Lactamase Inhibitors. Current Medicinal Chemistry, 11, 1951-1964. https://doi.org/10.2174/0929867043364847

[123] Pagani, L., Colinon, C., Migliavacca, R., Labonia, M., Docquier, J.D., Nucleo, E., Spalla, M., Bergoli, M.L. and Rossolini, G.M. (2005) Nosocomial Outbreak Caused by Multidrug-Resistant Pseudomonas aeruginosa Producing IMP-13 Metallo-Beta-Lactamase. Journal of Clinical Microbiology, 43, 3824-3828. https://doi.org/10.1128/JCM.43.8.3824-3828.2005

[124] Castanheira, M., Bell, J.M., Turnidge, J.D., Mathai, D. and Jones, R.N. (2009) Carbapenem Resistance among Pseudomonas aeruginosa Strains from India: Evidence for Nationwide Endemicity of Multiple Metallo- $\beta$-Lactamase Clones (VIM-2,-5,-6, and-11 and the Newly Characterized VIM-18). Antimicrobial Agents and Chemotherapy, 53, 1225-1227. https://doi.org/10.1128/AAC.01011-08

[125] Peleg, A.Y., Franklin, C., Bell, J.M. and Spelman, D.W. (2005) Dissemination of the Metallo-Beta-Lactamase Gene bla ${ }_{\mathrm{IMP}-4}$ among Gram-Negative Pathogens in a Clinical Setting in Australia. Clinical Infectious Diseases, 41, 1549-1556. https://doi.org/10.1086/497831

[126] Walsh, T.R., Toleman, M.A., Poirel, L. and Nordmann, P. (2005) Metallo- $\beta$ - Lactamases: The Quiet before the Storm? Clinical Microbiology Reviews, 18, 306-325. https://doi.org/10.1128/CMR.18.2.306-325.2005 
[127] Malkocoglu, G., Aktas, E., Bayraktar, B., Otlu, B. and Bulut, M.E. (2017) VIM-1, VIM-2, and GES-5 Carbapenemases among Pseudomonas aeruginosa Isolates at a Tertiary Hospital in Istanbul, Turkey. Microbial Drug Resistance, 23, 328-334. https://doi.org/10.1089/mdr.2016.0012

[128] Jaurin, B. and Grundstrom, T. (1981) AmpC Cephalosporinase of Escherichia coli K-12 Has a Different Evolutionary Origin from That of Beta-Lactamases of the Penicillinase Type. Proceedings of the National Academy of Sciences of the United States of America, 78, 4897-4901. https://doi.org/10.1073/pnas.78.8.4897

[129] Ouellette, M., Bissonnette, L. and Roy, P.H. (1987) Precise Insertion of Antibiotic Resistance Determinants into Tn21-Like Transposons: Nucleotide Sequence of the OXA-1 Beta-Lactamase Gene. Proceedings of the National Academy of Sciences of the United States of America, 84, 7378-7382. https://doi.org/10.1073/pnas.84.21.7378

[130] Gherardini, P.F., Wass, M.N., Helmer-Citterich, M. and Sternberg, M.J.E. (2007) Convergent Evolution of Enzyme Active Sites Is Not a Rare Phenomenon. Journal of Molecular Biology, 372, 817-845. https://doi.org/10.1016/j.jmb.2007.06.017

[131] Hall, B.G. and Barlow, M. (2005) Revised Ambler Classification of $\beta$-Lactamases. Journal of Antimicrobial Chemotherapy, 55, 1050-1051. https://doi.org/10.1093/jac/dki130

[132] Frere, J.M., Galleni, M., Bush, K. and Dideberg, O. (2005) Is It Necessary to Change the Classification of $\beta$-Lactamases? Journal of Antimicrobial Chemotherapy, 55, 1051-1053. https://doi.org/10.1093/jac/dki155

[133] Alderson, R.G., Barker, D. and Mitchell, J.B.O. (2014) One Origin for Metallo- $\beta$-Lactamase Activity, or Two? An Investigation Assessing a Diverse Set of Reconstructed Ancestral Sequences Based on a Sample of Phylogenetic Trees. Journal of Molecular Evolution, 79, 117-129. https://doi.org/10.1007/s00239-014-9639-7

[134] Hall, B.G., Salipante, S.J. and Barlow, M. (2003) The Metallo- $\beta$-Lactamases Fall into Two Distinct Phylogenetic Groups. Journal of Molecular Evolution, 57, 249-254. https://doi.org/10.1007/s00239-003-2471-0

[135] Brandt, C., Braun, S.D., Stein, C., Slickers, P., Ehricht, R., Pletz, M.W. and Makarewicz, O. (2017) In Silico Serine $\beta$-Lactamases Analysis Reveals a Huge Potential Resistome in Environmental and Pathogenic Species. Scientific Reports, 7, Article No. 43232. https://doi.org/10.1038/srep43232

[136] Silveira, M.C., da Silva, R.A., da Mota, F.F., Catanho, M., Jardim, R., Guimaraes, A. C. and Miranda, A.B. (2018) Systematic Identification and Classification of $\beta$-Lactamases Based on Sequence Similarity Criteria: $\beta$-Lactamase Annotation. Evolutionary Bioinformatics, 14, 1-11. https://doi.org/10.1177/1176934318797351 